University of Nebraska - Lincoln

DigitalCommons@University of Nebraska - Lincoln

Faculty Publications, Department of Psychology

Psychology, Department of

2002

\title{
Food sharing: A model of manipulation by harassment
}

Jeffrey R. Stevens

University of Nebraska-Lincoln, jstevens5@unl.edu

David W. Stephens

University of Minnesota - Twin Cities, steph031@umn.edu

Follow this and additional works at: https://digitalcommons.unl.edu/psychfacpub

Part of the Psychiatry and Psychology Commons

Stevens, Jeffrey R. and Stephens, David W., "Food sharing: A model of manipulation by harassment" (2002). Faculty Publications, Department of Psychology. 544.

https://digitalcommons.unl.edu/psychfacpub/544

This Article is brought to you for free and open access by the Psychology, Department of at DigitalCommons@University of Nebraska - Lincoln. It has been accepted for inclusion in Faculty Publications, Department of Psychology by an authorized administrator of DigitalCommons@University of Nebraska - Lincoln. 


\title{
Food sharing: A model of manipulation by harassment
}

\author{
Jeffrey R. Stevens and David W. Stephens
}

Department of Ecology, Evolution, and Behavior, University of Minnesota, 1987 Upper Buford Circle, St. Paul, MN 55108, USA

Corresponding author - J. R. Stevens

\begin{abstract}
Most analyses of food-sharing behavior invoke complex explanations such as indirect and delayed benefits for sharing via kin selection and reciprocal altruism. However, food sharing can be a more general phenomenon accounted for by more parsimonious, mutualistic explanations. We propose a game theoretical model of a general sharing situation in which food owners share because it is in their own self-interest - they avoid high costs associated with beggar harassment. When beggars harass, owners may benefit from sharing part of the food if their consumption rate is low relative to the rate of cost accrual. Our model predicts that harassment can be a profitable strategy for beggars if they reap some direct benefits from harassing other than shared food (such as picking up scraps). Therefore, beggars may manipulate the owner's fitness payoffs in such a way as to make sharing mutualistic.
\end{abstract}

Keywords: food sharing, harassment, manipulation, mutualism, game theory

$\mathrm{R}$ ed colobus monkeys (Colobus badius) are an important and desirable source of protein for chimpanzees (Pan troglodytes; Goodall, 1986). A monkey kill attracts beggars that sidle up to the carcass owner, extend their hands, vocalize, and sometimes grab a scrap of meat. In some situations, the carcass owner may share with the beggar, breaking off a piece of meat and handing it to a beggar. Why would the owner give away food that it could consume?

Food sharing, defined here as joint use of a monopolizable food source, can be as active as this chimpanzee example or as passive as a lioness allowing another lioness to feed on her gazelle carcass. Either way, sharing appears to exemplify animal altruism because one individual accepts a fitness cost while another receives a fitness benefit. Although sharing may be altruistic at the time of the sharing event, mechanisms such as kin selection (Hamilton, 1964) and reciprocal altruism (Trivers, 1971) may provide indirect or delayed benefits to the sharer (de Waal, 1989; Mitani and Watts, 2001; Perry and Rose, 1994). In the case of reciprocal altruism, the food is recouped in the future; thereby making sharing altruistic in the short term but selfish in the long term. The complicated cognitive machinery necessary for reciprocal altruism and the presence of relatives necessary for kin selection make these explanations limited in the contexts in which they apply. If, however, sharing leads to an immediate gain for the owner, the situation becomes much more general, and the more complex, long-term accounts are unnecessary. Applying resource defense theory (Brown, 1964; Ydenberg et al., 1986) to our general concept of sharing allows us to consider unexplored explanations of sharing: nonfood owners may harass or interfere with the owner's feeding, thereby making it uneconomical to defend the food.

In our chimpanzee example, a beggar may harass the owner for food by screaming, grabbing at the carcass, or stealing the entire carcass. Often the owner defends its carcass, thus risking injury and incurring energetic costs, opportunity costs of slowing feeding rate, and other costs such as attracting more beggars. The beggar faces similar but probably reduced costs of its own when harassing. Therefore, the beggar can influence the net payoffs to the owner by inflicting or withholding the costs of harassment. If the costs of harassment are large, sharing might yield a higher net benefit to the owner than defending. If the beggar alters the owner's net benefits enough to change the owner's optimal strategy, the beggar has manipulated the payoffs in a way that makes sharing in the owner's immediate self-interest (i.e., sharing becomes mutualistic). This manipulative mutualism may occur commonly in situations in which an actor's behavior manipulates the net payoffs for another individual's cooperative behavior, making cooperation mutualistic rather than altruistic.

Harassment is a particularly interesting factor that may influence sharing across many situations and taxa because the beggar's actions rather than extrinsic forces (such as patch profitability or travel time) determine the owner's payoffs and optimal decision. To analyze the effect of harassment on food sharing explicitly, we consider an asymmetric game theoretical model. This model is one of only a few models of food sharing and, more important, one of the first to analyze the potential immediate fitness benefits associated with food sharing. This model examines the circumstances under which harassment and sharing should occur as well as optimal amounts of harassment and sharing.

\section{Model}

\section{Elements of the sharing/harassment game}

Consider two animals: a resource owner, who possesses a valuable food item of size $A$ (for amount), and a beggar, who has nothing but is aware of the owner's food item. Both individuals may forage elsewhere, but this food item offers a much more valuable fitness benefit per unit time. The owner may choose to share a portion of its food, say $A_{s}$ (for amount shared). The beggar can choose to harass the owner or leave him alone. We express the beggar's harassment intensity as a rate, $c$ (e.g., measured in calories per second). If the beggar harasses the owner for time $t$, this costs the beggar $c t$, and it costs the owner $\gamma \cdot c t$ (where $\gamma$ represents a conversion factor that captures how the beggar's harassment affects the owner). We assume that the beggar harasses at intensity $c$ when it is not busy eating; that is, while the beggar consumes shared food, it does not or cannot harass. 
Consumption and time available for harassment. We base our model on time in the sense that we calculate the costs and benefits in terms of the time engaged in various activities and corresponding rates of expenditure during these activities. We assume that both players consume food at rate $r$, so a single animal consuming the entire resource (amount $A$ ) will spend time $A / r$ eating. Next, we express the time available for harassment $\left(T_{h}\right)$ in the form

$$
T_{h}=\frac{A}{r} \pi(p)
$$

where $p$ represents the proportion of $A$ that the owner shares (i.e., $\left.p=A_{\delta} / A\right)$. The function $\pi(p)$ gives the proportion of the maximum consumption time $(A / r)$ that is available for harassment. If the owner shares nothing, the beggar has the entire time available for harassment, so we expect that $\pi(0)=1$. Similarly, if the owner gave everything away, the beggar would have no time available to harass, so we expect that $\pi(1)=0$. More generally, we expect that the time available for harassment will decrease as the proportion shared increases.

In this game, then, the owner influences the cost and duration of harassment by controlling $A_{s^{\prime}}$ while the beggar influences the cost of harassment by controlling the harassment intensity $c$.

\section{The simplest game}

Using these assumptions, we can write down the benefits to the owner $\left(B_{o}\right)$ as a function of the proportion of $A$ shared (denoted by $p$ ) and intensity of harassment $c$ :

$$
B_{o}(p, c)=A-p A-\frac{c \gamma A}{r} \pi(p)=A\left[1-p-\frac{c \gamma}{r} \pi(p)\right]
$$

The benefits obtained by the beggar, $B_{b^{\prime}}$ also depend on the proportion shared and the intensity of harassment:

$$
B_{b}(p, c)=p A-\frac{c A}{r} \pi(p)=A\left[p-\frac{c}{r} \pi(p)\right]
$$

In the next step in finding a solution to the game, we ask how the owner's choice of $p$ affects the beggar's optimal $c$ and vice-versa.

No share/no harass. The simple structure of $B_{b}(p, c)$ leads us to a simple conclusion. "No sharing" $(p=0)$ and "no harassment" $(c=0)$ is the only Nash equilibrium of the game as currently constituted (a strong Nash equilibrium is equivalent to an evolutionarily stable strategy, or ESS; Maynard Smith, 1982). The beggar's benefits can only decrease with increasing harassment intensity $\left(d B_{b} / d c=\pi(p) / r\right)$, meaning that $c=0$ is the beggar's best option regardless of the owner's behavior. A nonzero harassment intensity cannot persist because, according to Equation 3, a beggar that reduces its harassment intensity always increases the benefits it obtains. In turn, this means that $p=0$ represents the owner's best choice because $B_{o}(p, 0)=A(1$ $-p$ ) can only decrease with increasing $p$. This result may seem disappointing because no sharing and no harassment make for an uneventful interaction. We believe, however, that it reflects a common natural situation: when an owner possesses a completely defendable resource, a harasser only incurs costs by harassing, and it only benefits by recognizing the possessor's ownership and moving on to some other possibility.

\section{Noncontingent benefits of harassment}

This situation can change if harassment has some direct benefits that accrue even if the owner does not share. A harasser may, for example, collect scraps, cause a distracted owner to spill, or actively steal parts of the resource. We call these gains the "noncontingent benefits" of harassment because they do not depend on the owner's sharing.

Modeling noncontingent benefits. We suppose that these noncontingent benefits should increase with the intensity of harassment, $c$, and with the time available for harassment, $(A / r)$ $\pi(p)$. With these in mind, we can rewrite our benefit functions as

$$
\begin{aligned}
B_{o}(p, c) & =A-p A-\frac{c \gamma A}{r} \pi(p)-\frac{c k A}{r} \pi(p) \\
& =A\left[1-p-\frac{c(\gamma+k)}{r} \pi(p)\right]
\end{aligned}
$$

for the owner, and

$$
\begin{aligned}
B_{b}(p, c) & =A p-\frac{c A}{r} \pi(p)+\frac{c k A}{r} \pi(p) \\
& =A\left[p+\frac{c(k-1)}{r} \pi(p)\right]
\end{aligned}
$$

for the beggar, where $k$ represents a factor that measures the noncontingent benefits of harassment. We assume that the noncontingent benefits depend on the intensity of harassment (more harassment yields more benefits); thus $k$ is proportional to $c$. Notice that we subtract the noncontingent gains from the owner's benefits because we assume that any benefit that the beggar derives from resource $(A)$ comes at the owner's expense.

A noncontingent benefit factor $k$ can destabilize the no share/no harass equilibrium by making harassment worthwhile in its own right. Generally speaking, if $k>1$, the beggar can benefit from harassment regardless of the owner's behavior, and the beggar's optimal harassment level $(\hat{c})$ should be the maximum intensity, say $c^{*}$. If, however, $k<1$, the beggar should not harass, and no share/no harass is the only equilibrium.

\section{The owner's problem and the $\pi(p)$ function}

We expect that the beggar should either not harass $(\hat{c}=0)$ or harass at the maximal intensity $\left(\hat{c}=c^{*}\right)$. To study whether the owner should share when harassed, and if so, how much, we need to know more about the function $\pi(p)$ that specifies the proportion of the maximum consumption time available for harassment. In the Appendix we derive a $\pi(p)$ function using a stochastic model of the sharing process. This model assumes that the resource is subdivided into $n$ discrete pieces, with the owner deciding whether to share each chunk with probability $p$. Notice that this subtle reinterpretation of $p$ means that we should think of $p$ as the average proportion shared, rather than the realized proportion shared-technically, we now have $A p$ $=E\left(A_{s}\right)$, instead of $A p=A_{s}$. If the resource is not divisible $(n=$ $1), \pi(p)$ decreases linearly with $p$ with a slope of $-1\left[\pi^{\prime}(p)=-1\right.$; Figure 1]. For divisible resources $(n>1)$, the $\pi(p)$ function has a slope of -2 at $p=0$, increases in slope around $p=.5$, and has a slope of 0 at $p=1$ (Figure 1). Regardless of divisibility, $\pi(p)$ always decreases with $p$.

Optimal sharing when harassed. With the basic properties of $\pi(p)$ in hand, we can now show how harassment should affect the owner's willingness to share $(p)$. To begin, we differentiate the owner's benefit function (Equation 4):

$$
\frac{d B_{o}}{d p}=A\left[-1-\frac{c(\gamma+k)}{r} \pi^{\prime}(p)\right]
$$

For indivisible resources $(n=1), \pi^{\prime}(p)=-1$, and 


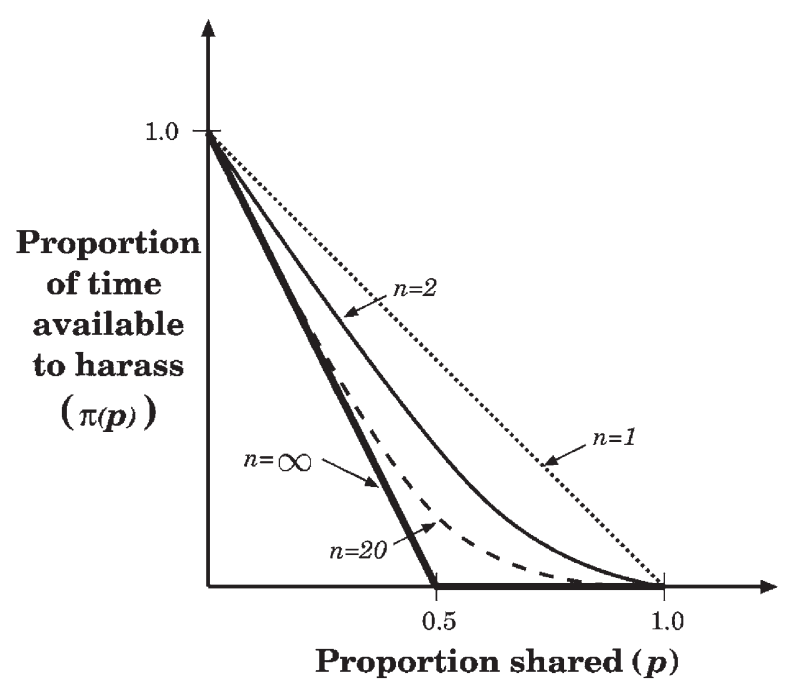

Figure 1. The proportion of time available to harass always decreases with the proportion shared. In the simplest case (Equation A1), the time available to harass decreases linearly to zero as the owner shares up to half of the resource, and if the owner shares more than half of the resource, the beggar never has the opportunity to harass (thick line). By incorporating resource divisibility or $n$ (equation A2), we smooth the "kinked" property of the function (all other lines). Increasing divisibility $(n)$ approaches the simpler kinked function.

$$
\frac{d B_{o}}{d p}=A\left[-1+\frac{c(\gamma+k)}{r}\right]
$$

We predict, therefore, that the owner should defend an indivisible resource $(\operatorname{set} p=0)$ when

$$
\frac{r}{c(\gamma+k)}>1
$$

and abandon it (set $p=1)$ when

$$
\frac{r}{c(\gamma+k)}<1
$$

The dimensionless term $r / c(\gamma+k)$ plays an important role in our model. The numerator includes the food consumption rate, and the denominator expresses the rate at which costs accrue during harassment. It represents, therefore, an efficiency - a quotient of rate of benefit gain over rate of cost accrual, and we call it the " efficiency of consumption when harassed" (ECH).

A divisible resource, however, complicates the analysis. Because $\pi^{\prime}(0)=-2$, we know that the owner maximizes its benefits at $p=0$ (no sharing) when

$$
\begin{gathered}
-1+\frac{2 c(\gamma+k)}{r} \leq 0 \quad \text { or } \\
\frac{r}{c(\gamma+k)} \geq 2
\end{gathered}
$$

That is, the owner should share a divisible resource only when the $\mathrm{ECH}$ is $<2$.

Optimal amount to share. If $2>r / c(\gamma+k) \geq 0$, then we expect the owner to share some portion of a divisible resource (Figure 2). Although the complexity of $\pi(p)$ prevents a general algebraic specification of the optimal $p$ (or $\hat{p})$, a graphical method gives a relatively complete characterization. The $\hat{p}$ value is the solution of

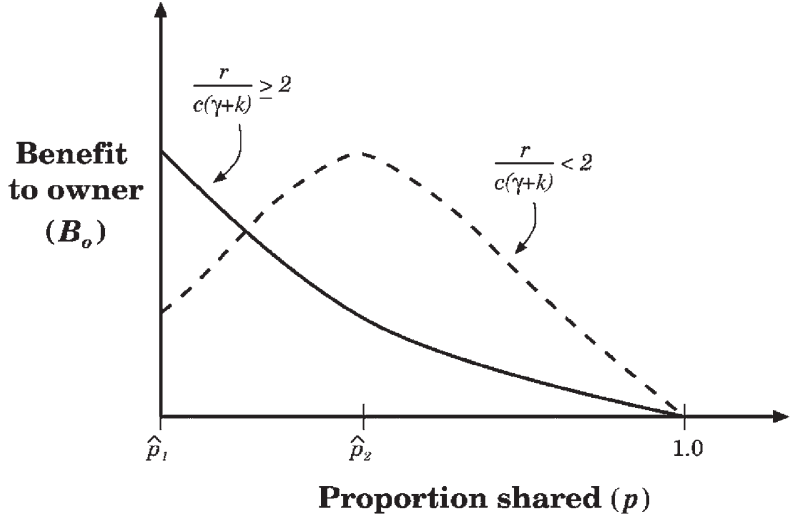

Figure 2. To determine the optimal proportion to share, we maximize the owner's benefit $\left(B_{o}\right)$ as a function of proportion shared $(p)$. If this maximum is $\leq 0$ (negative derivative at $p=0$ ), the owner should not share $\left(\hat{p}_{1}=0\right)$. If this maximum is $>0$, the owner should share an intermediate amount $\left(\hat{p}_{2}>0\right.$; Equation 10).

$$
\frac{r}{c(\gamma+k)}=-\pi^{\prime}(p)
$$

Because $\pi^{\prime}(p)$ is an increasing sigmoid function of $p,-\pi^{\prime}(p)$ is a sigmoid function that decreases from 2 at $p=0$ to 0 at $p$ $=1$. Figure 3 shows how $\hat{p}$ is related to the term $r / c(\gamma+k)$. To find $\hat{p}$ corresponding to a given $r / c(\gamma+k)$, we locate $r / c(\gamma+k)$ on the vertical axis and trace a horizontal line to the sigmoid $-\pi(p)$ curve, then we trace a vertical line to $p$ axis to the find $\hat{p}$. This graphical solution gives a relatively complete picture of the economics of sharing: (1) $\hat{p}$ increases as $r / c(\gamma+k)$ decreases; (2) if $r / c(\gamma+k) \geq 2, \hat{p}=0$; (3) if $2>r / c(\gamma+k) \geq 1$ then $.5 \geq \hat{p}>0$; (4) if $1>r / c(r+k) \geq 0$ then $1 \geq \hat{p}>.5$.

In addition, this graphical solution shows the effect of resource divisibility. For a more divisible resource (higher $n$ ), the sigmoid function will be more abrupt and steplike (Figure 3B), shifting optimal sharing proportions closer to one-half.

Assembling the pieces. Now that we have a reasonably complete picture of the owner's and beggar's options, we assemble these pieces into a game theoretical analysis. The simple form of the beggar's problem makes this job easier because we only have to consider $\hat{c}=0$ and $\hat{c}=c^{*}$ (where $c^{*}$ is the maximal intensity). This simplifies things because we only need to consider two possibilities for the owner as well: the best reply to zero harassment and the best reply to maximal harassment. As discussed above, the owner's best reply to no harassment is no sharing $(\hat{p}=0)$. We denote the best reply to maximal harassment as $p^{*}$ and remark that this is given by:

$$
\begin{gathered}
p^{*}=0 \quad \text { if } \quad \frac{r}{c(\gamma+k)} \geq 2 \\
\frac{r}{c(\gamma+k)}=-\pi^{\prime}\left(p^{*}\right) \quad \text { otherwise. }
\end{gathered}
$$

Since we have two alternatives for each player $(\hat{c}=0$ or $\hat{c}=$ $c^{*}$ for the beggar and $\hat{p}=0$ or $\hat{p}=p^{*} \neq 0$ for the owner), we can gain some intuition about the game using the familiar tool of the two-by-two game matrix, as shown in Figure 4.

We can now characterize all possible Nash equilibria (share/ no harass is never an equilibrium; Figure 5):

1. No share/no harass. If $k<1$, the noncontingent benefits of harassment are too small, so the beggar should not harass, and as a consequence the owner should not share. 


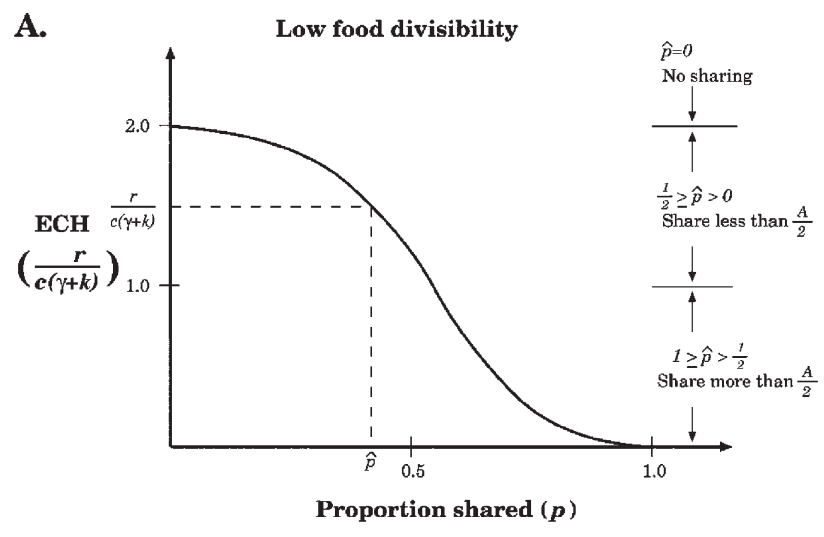

B.

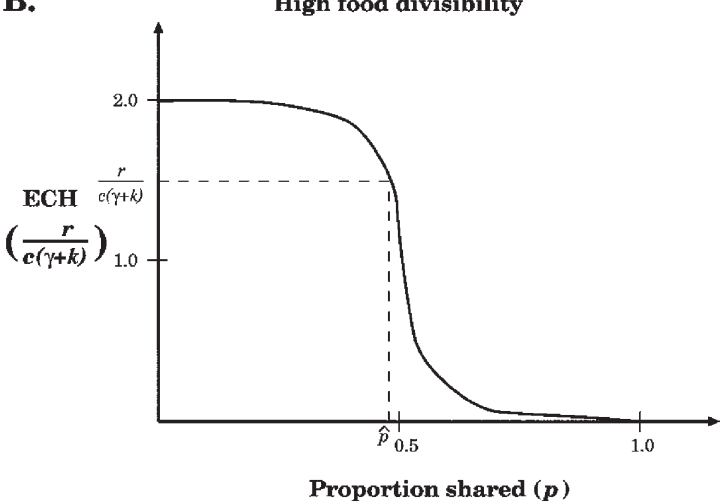

Figure 3. With low resource divisibility (A), the optimal proportion to share $(\hat{p})$ is relatively low for a given efficiency of consumption when harassed (ECH). With high resource divisibility (B), $\hat{p}$ approaches onehalf for the same ECH.

2. No share/harass. If $k>1$ and $r / c^{*}(\gamma+k) \geq 2$, noncontingent benefits make harassment worthwhile for the beggar, but sharing does not benefit the owner because of the high $\mathrm{ECH}$. That is, harassment has little effect on the owner's consumption rate.

3. Share/harass. If $k>1$ and $r / c^{*}(\gamma+k)<2$, again, noncontingent benefits make harassment worthwhile for the beggar, but now sharing benefits the owner because of high costs of harassment relative to the rate of food consumption (low ECH).

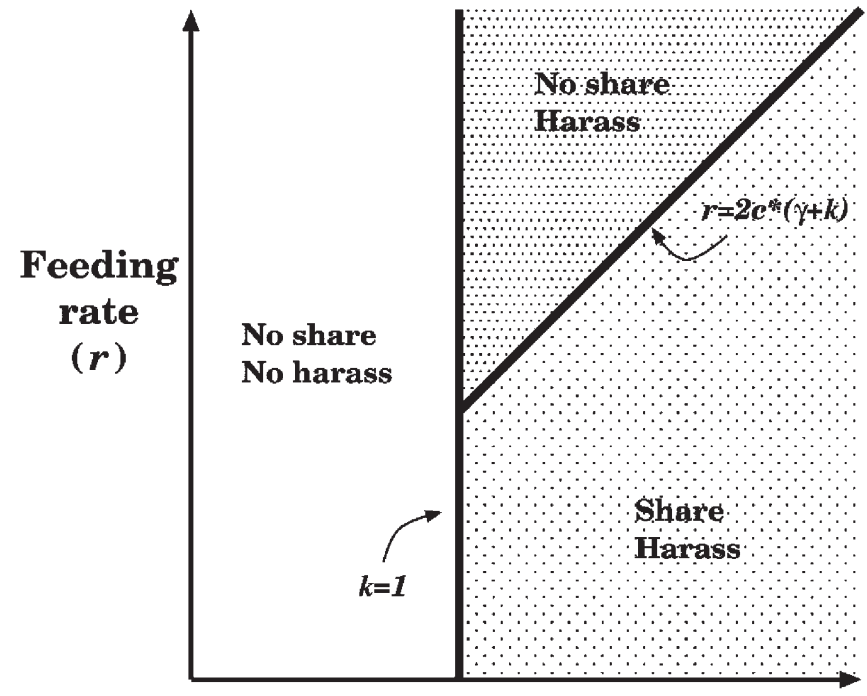

Non-contingent benefits $(k)$

Figure 5. The three possible Nash equilibria depend on noncontingent benefits $(k)$ and feeding rate $(r)$.

\section{Model discussion and conclusions}

Now we review and highlight several key features and variables of the model. First, notice that adopting the maximum harassment intensity, $c^{*}$, does not necessarily mean that the beggar will spend much time harassing the owner. Our model assumes that beggars harass only when not consuming shared food. Considering the three equilibria listed above, then, we would expect the most harassment in the no share/ harass case, the least harassment in the no share/no harass case, and an intermediate amount in the share/harass case.

The parameter $k$ measures the noncontingent benefits of harassment and is probably the most important variable in the model. The condition $k>1$ simply means that the benefits of harassment must outweigh the costs even if the owner does not share. An animal that harasses when $k<1$ simply burns its own resources (and an owner's best strategy is to let the harasser do so). Our model's second key parameter, the efficiency of consumption when harassed, or ECH $\left[r / c^{*}(r\right.$ $+k)]$, measures the speed of food intake relative to the cost rate of harassment. The role of intake rate $(r)$ agrees with in-

\section{BEGGAR}

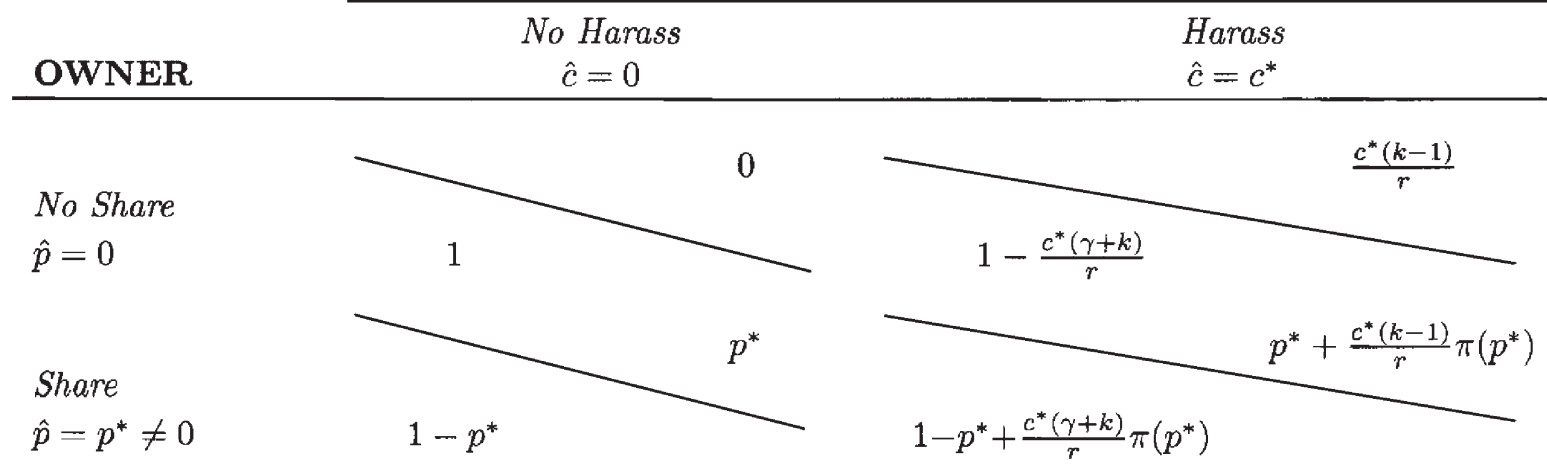

Figure 4. Two-by-two game matrix representing the harassment game. 
tuition, for we do not expect sharing of small or easily processed resources.

Given that the resource is divisible $(n>1)$, the amount of divisibility does not affect the equilibria outlined above, but it should affect the proportion shared when sharing occurs. Our model predicts that the amount shared should approach one-half as resource divisibility increases (Figure 3). One-half is special in our model because we assume that both players feed at the same rate. It follows that if the owner wants to eat the maximum amount in peace (keeping the beggar occupied while it eats), then a 50/50 split will achieve this goal.

\section{DISCUSSION}

Our model explores the effects of harassment on food sharing. For harassment to be profitable, the beggar must receive benefits for harassing (high $k$ ) whether or not the owner shares (e.g., gathering scraps, stealing small pieces). In the face of this harassment, an owner may share if harassment sufficiently reduces its feeding efficiency $\left[r / c^{*}(\gamma+k)\right]$.

\section{Importance and implications}

\section{Harassment and manipulation}

As one of the first models to explicitly examine immediate benefits of food sharing, we set the stage for more general or parsimonious explanations of sharing than kin selection and reciprocal altruism (de Waal, 1989; Perry and Rose, 1994). Clutton-Brock and Parker (1995) reviewed general forms of manipulation and punishment in animal societies, but only two studies provide evidence that harassment influences animal sharing. First, Wrangham (1975) suggested that harassment may play a large role in chimpanzee sharing of colobus monkey meat after kills. These kills often attracted beggars that vocalized, used begging hand gestures, and even attacked the owner (Goodall, 1986; Wrangham, 1975). If the owner shared part of the food, the recipient usually left, followed by a small band of beggars. Wrangham (1975) hypothesized that the owners "paid" the beggars with pieces of food to avoid harassment. More recent evidence indicates that chimpanzees that harass intensely receive more food than those that harass less intensely (Gilby IC, unpublished data).

Hauser and Marler (Hauser, 1992; Hauser and Marler, 1993) described an extreme example of harassment affecting food sharing. In experiments involving rhesus macaques (Macaca mulatta), Hauser and colleagues provided food to individual monkeys that were out of view of other monkeys. They found that, when detected by others, monkeys that did not give food recruitment calls experienced more aggression than monkeys that called. Calling females consumed more food than silent females because silent females dropped food while being chased (Hauser, 1992). The increase in callers' consumption indicates that calling may be immediately mutualistic.

\section{Noncontingent benefits}

Our model emphasizes benefits that beggars receive even if the owner defends the food; that is, the owner cannot unilaterally defend the entire food source, so harassing the owner to gather scraps or steal pieces of food may benefit the beggar. Without these incentives to remain close to the owner, harassment is not profitable, and in the absence of harassment, the owner has no incentive to share.

Kummer and Cords (1991) conducted experiments on captive long-tailed macaques (Macaca fascicularis), varying non- contingent benefits for non-food owners. They found that non-food owners tended to harass more (via stealing, stealing attempts, and food manipulation) when the owner could not completely control the food than when it could control the food. Unfortunately, the authors did not present data on the non-food owner's success rate for obtaining food.

\section{Resource divisibility}

Our finding that resource divisibility does not affect the owner's decision to share is a bit curious. Although it does not directly influence sharing, divisibility may indirectly influence the decision to share if it affects the noncontingent benefits of harassment. We did find, however, that divisibility determines the proportion of the food source that the owner should share if it does share: owners should share about one-half of highly divisible food.

Consider a lioness consuming a freshly killed gazelle. A single lioness can defend an intact carcass, but when the carcass begins to disintegrate, the lioness may have difficulty defending the entire carcass, and she may allow others to take small pieces. Elgar (1986) suggested that, upon discovery of a food source, house sparrows (Passer domesticus) sparrows gave "chirrup" calls, thereby attracting conspecifics and decreasing individual predation risk. Interestingly, the sparrows called more frequently after discovering a divisible food source than a solid source. Hauser et al. (1993) reported similar results with chimpanzees: individuals gave more food-associated calls when consuming a divided watermelon than when consuming an intact watermelon. Perhaps frequent sharing of a divisible food source is simply a question of sheer monopolizability. Defending multiple food sources may prove much more difficult than defending a single source.

\section{Latent harassment}

In natural situations in which owners defend food before sharing (such as in chimpanzees), harassment is obvious. In situations in which the owner shares immediately, however, blatant harassment may not appear even if the ever-present threat of harassment maintains the sharing. Of course, latent harassment may prove difficult to observe in nature, necessitating empirical manipulations of sharing and potential for harassment. In a related vein, the overt harassment and food defense may be an information-gathering ritual for both the owner and beggar; each one gauging the other's motivation and resolve (see Ydenberg et al., 1986, for applications of the war of attrition to resource defense).

\section{Related models}

Although few models directly focus on the immediate benefits of food sharing (but see Giraldeau and Caraco, 2000; Mesterton-Gibbons and Dugatkin, 1999), several classes of models lay the foundation for theoretically exploring the evolution of food sharing.

\section{Resource defense}

Whereas the term "sharing" often evokes thoughts of one individual actively donating food to another, sharing can be much more generally defined in terms of two or more individuals consuming a resource that one can monopolize. This broader concept of sharing encompasses many instances of resource defense. Brown (1964) originally described the " economic defendability" of territory defense as the circumstances under which an individual should accept the costs involved 
in defending a territory. Others have extended this work to the defense of food sources. Ydenberg et al. (1986) modeled the defense of food sources in a way relevant to this model by considering the effects of interference (analogous to our harassment) on foraging decisions. Their model predicted that interference will slow intake rate, thereby making defense uneconomical for individuals that are far from their home and for those with richer food patches in their home range. The combined effect of interference and the asymmetries in homerange distance and richness may allow subordinate individuals to feed in patches with dominant individuals or even interfere with and exclude dominant individuals from patches.

\section{Tolerated theft}

Blurton Jones $(1984,1986,1987)$ argued that an asymmetry of value based on satiety might be important in tolerated theft situations. Although the next morsel of food is not very important to the sated owner, it may be very valuable to the hungry beggar. Because of this decrease in the marginal value of food during consumption, the owner should tolerate theft of food by the beggar.

Although this idea provided a valuable foundation for modeling food sharing, the important aspect of behavior in game theory is the relative value of an individual's options, not the value difference between individuals. Blurton Jones mentioned that owners must weigh the costs of defending food, but never incorporated this idea into the model. Without this key inclusion, the analysis ignores strategy stability. Winterhalder (1996a, 1996b) continued the marginal analysis of tolerated theft, but still did not apply a game theoretical approach.

\section{Producer/scrounger games}

Our model examines the conditions under which a non-food owner benefits by harassing an owner and an owner benefits by sharing with the beggar. The producer-scrounger game (Barnard and Sibly, 1981; Vickery et al., 1991) addresses whether individuals specialize in either searching for food individually (producing) or avoiding costs of foraging by parasitizing the finds of the producers (scrounging); thereby assuming that harassing and sharing occur. Keep in mind, however, that individuals can choose between the two strategies; that is, for any given foraging bout, an individual is either a producer or scrounger, but it can choose either strategy in a future bout. Giraldeau and colleagues have experimentally investigated theory-based predictions on the effects of dominance, resource divisibility, role specialization, patch departure time, and competition intensity in a producer-scrounger situation (Beauchamp and Giraldeau, 1997; Giraldeau et al., 1990).

\section{Extensions}

\section{Destabilizing the no share/no harass equilibrium}

In our model, harassment can only persist when harassing produces noncontingent benefits for the harasser, and this result has led us to hypothesize that phenomena such as stealing and scrap collecting are prerequisites to harassment-induced sharing. We do not, of course, claim that this is the only way to destabilize the no share/no harass equilibrium, but it does seem to be a plausible and parsimonious approach. This result arises in our model because we assume that the beggar's gains change linearly with harassment intensity, so that the optimal harassment intensity must be either the minimum level (0) or the maximum level $\left(c^{*}\right)$. Future work, ideally guided by empirical results, might explore nonlinear benefit functions which can (in theory) destabilize the no share/no harass equilibrium without noncontingent benefits.

\section{Food consumption rate}

Food consumption rate $(r)$ is an important parameter in our model. We assume that the players have similar consumption rates, which means that the amount required to keep a harasser busy is similar to the amount the owner will be able to eat in peace. In natural situations, consumption rates may be quite different because of differences in sex, age, or levels of satiety. Systematic variation in individual consumption rates may provide an interesting avenue to explore both theoretically and empirically. An informal application of our model's logic suggests that differential consumption rates may influence the beggar's decision to harass and the owner's decision to share and how much to share. For example, owners may be more willing to share with slow eaters (e.g., juveniles who have not learned efficient food handling techniques) because they can be kept busy at minimal cost.

\section{$N$-player game}

Our model considers only two players to simplify the problem and to conform to a standard two-by-two game matrix. In natural situations, however, multiple beggars often surround an owner. We speculate that including multiple beggars in our model will increase the overall intensity of harassment, thereby forcing the owner to share more frequently (any parent knows it is easier to tolerate harassment from one child than from several children). Chapman and Kramer (1996) found experimentally that as the number of food competitors increased, the owner's intake rate decreased, guarding success decreased, and total number of chases peaked at intermediate competitor numbers. The difficulty in analyzing the effects of beggar number on sharing lies in how to distribute the food in such a way to minimize harassment costs when facing multiple beggars. Further analysis is necessary to explore optimal amounts of food that an owner should share with multiple beggars: should the owner share one large piece to draw some of the beggars away, or should it share small pieces with every beggar?

The optimal strategy of the beggars offers a challenge as well. One can imagine multiple beggars in a situation similar to that of a group of vigilant prey. Like the concept of corporate vigilance (Bertram, 1980), a beggar would probably benefit more from having additional beggars around to increase chances of sharing. Packer and Abrams (1990) modeled vigilance situations and found that Nash equilibrium vigilance levels were often lower than Pareto equilibrium (or co-operative optimum) vigilance levels. Similarly, food beggars are tempted to cheat or not harass by relying on harassment by others, thereby avoiding their own costs of harassment.

\section{Summary}

Using a game theoretical approach, we modeled the effects of harassment on food sharing. Our model predicts that a nonfood owner should harass an owner when the nonowner can gain benefits even in the absence of sharing. These non-contingent benefits (such as gathering dropped scraps) can recoup energetic costs of harassing. An owner should only share when a beggar harasses, significantly reducing its consumption rate. Therefore, if an owner consumes the food slowly, a beggar can harass for long periods of time, so the owner pays high costs of defending. Experimentally manipulating parameters such as feeding rate, noncontingent benefits, resource divisibility, and number of beggars in a sharing context could provide rigorous tests of our model. 


\section{APPENDIX}

\section{The $\pi(p)$ function and time available for harassment}

Here we determine how the amount shared, $A_{s^{\prime}}$ influences the time available for harassment. Because we assume that both players feed at rate $r$, the owner consumes for time

$$
\frac{A-A_{s}}{r}
$$

while the beggar consumes for time

The difference

$$
\frac{A_{s}}{r}
$$

$$
\frac{A-A_{s}}{r}-\frac{A_{s}}{r}=\frac{A-2 A_{s}}{r}
$$

represents the time available for harassment, with the proviso that a negative value means zero time available for harassment (because the beggar spends longer eating than the owner). If we let $T_{h}$ represent the time available for harassment, then we have

$$
T_{h}=\left\{\begin{array}{lc}
\frac{A-2 A_{s}}{r} & \text { if } A_{s} \leq \frac{A}{2} \\
0 & \text { otherwise }
\end{array}\right.
$$

Substituting this into Equation 1 suggests a $\pi(p)$ function of the form

$$
\pi(p)= \begin{cases}1-2 p & \text { if } p \leq .5 \\ 0 & \text { otherwise }\end{cases}
$$

so that $T_{h}=(A / r) \pi(p)$ as required. Figure 1 uses Equation A1 to plot $\pi(p)$ as a function of the proportion shared $p$. Although one might construct a model based on the "kinked" $\pi(p)$ function (Figure 1) discussed above, it is both inconvenient and implausible. It is inconvenient because the discontinuity at $p=.5$ means that all remaining calculations must also take account of this condition. It is implausible because stochastic variation in consumption rates $(r)$ and the amount shared $\left(A_{\mathrm{s}}\right)$ will combine to create smooth expected harassment time curve $\left[E\left(T_{h}\right)\right]$. The next few paragraphs discuss one simple way to incorporate this stochasticity.

\section{Resource divisibility and binomial sharing}

Some resources divide easily into parts, whereas others cannot. Suppose that the resource in question can be divided into $n$ equal parts of size $A / n$. Now suppose that when the owner chooses the proportion to share, $p$, it determines the probability of sharing each part. In this scenario the number of parts shared is a random variable drawn from a binomial distribution with parameters $p$ and $n$, where $p$ represents the owner's willingness to share $\left(p=A_{g} / A\right)$, and the $n$ represents the divisibility of the resource.

The assumption that a binomial process governs sharing allows us to specify completely the expected time available for harassment given the owner's willingness to share, $p$. If the owner shares $m$ of the $n$ parts, the owner retains amount

$$
\frac{(n-m) A}{n}
$$

and the beggar obtains amount

$$
\frac{m A}{n}
$$

Because we assume that both animals feed at the same rate $(r)$, the time available for harassment is the difference

$$
T_{h}=\frac{(n-m) A}{r n}-\frac{m A}{r n}=\frac{A(n-2 m)}{r n}
$$

as long as $n-2 m$ is positive. If not, the beggar has more food than the owner, and it will continue eating even after the owner has finished. So there is no time available for harassment $\left(T_{h}=0\right)$ if $m \geq n / 2$. To find the expected time available for harassment $\left[E\left(T_{h}\right)\right]$, we calculate the product of the time available $\left(T_{h}\right)$ and the probability of $m$ pieces being shared, summed over every possible $m$. We use

$$
\left(\begin{array}{c}
n \\
m
\end{array}\right) p^{m}(1-p)^{n-m}
$$

as the binomial probability of sharing $m$ pieces (Zar, 1996).

$$
E\left(T_{h}\right)=\frac{A}{r} \underbrace{\sum_{m=0}^{m<n / 2} \frac{(n-2 m)}{n}\left(\begin{array}{c}
n \\
m
\end{array}\right) p^{m}(1-p)^{n-m}}_{\pi(p)}
$$

where the indicated portion of this expression is the $\pi(p)$ function that we seek. Figure 1 shows this $\pi(p)$ function for a range of resource divisibilities ( $n$ values). The figure compares this family of $\pi(p)$ functions to the piecewise function (Equation A1) obtained when we assume infinite divisibility and errorfree sharing. For indivisible resources $(n=1), \pi(p)$ is a straight line $[\pi(p)=1-p$; Figure 1]. As resource divisibility increases, $\pi(p)$ approaches the piecewise function derived earlier (Equation A1; see Figure 1).

Although we cannot express $\pi(p)$ in an algebraically convenient closed form, we can easily state the important properties of $\pi(p)$. The most important feature of $\pi(p)$ is its derivative at zero $\left[\pi^{\prime}(0)\right]$. Direct differentiation shows

$$
\pi^{\prime}(0)= \begin{cases}-1 & \text { if } n=1 \\ -2 & \text { if } n \geq 2\end{cases}
$$

that is, the derivative at zero is -1 for indivisible resources and -2 otherwise. Moreover, for divisible resources, the derivative at $p=1$ is zero $\left[\pi^{\prime}(1)=0\right]$. In the indivisible case, $\pi(p)=1-p$, so $\pi^{\prime}(p)=-1$ for all $p$. Finally, we observe that $\pi(p)$ decreases with $p$ (technically, it is nonincreasing with $p$ ).

\section{Index of variables}

A entire resource amount

$A_{\mathrm{s}} \quad$ amount owner shares with beggar

$B_{\mathrm{b}} \quad$ fitness benefits received by beggar

$B_{\mathrm{o}} \quad$ fitness benefits received by owner

C intensity of harassment

$c^{*} \quad$ maximum intensity of harassment

$\hat{c} \quad$ optimal intensity of harassment

$\mathrm{ECH}$ efficiency of consumption when harassed

$k$ noncontingent benefits factor

$m$ number of discrete parts of resource shared by owner

$n$ total number of discrete parts of resource

$p \quad$ proportion of total amount shared

$p^{*} \quad$ proportion of total amount shared that is optimal reply to $c^{*}$

$\hat{p} \quad$ optimal proportion of total amount shared

$r \quad$ consumption rate

$t \quad$ total harassment time

$T_{\mathrm{h}} \quad$ time available for harassment

$r$ effect of beggar's harassment intensity on owner's fitness

$\pi(p) \quad$ proportion of maximum consumption time that is available for harassment when owner shares $p$ proportion of food 
Acknowledgments - We thank Ian Gilby, Craig Packer, Alison Pearce, and two anonymous referees for reviewing the manuscript. We thank the Packer/Pusey/Stephens lab group at the University of Minnesota for stimulating discussions on this topic. This project was funded by the National Science Foundation grant IBN-9896102 (to D.W.S.).

\section{REFERENCES}

Barnard CJ, Sibly RM, 1981. Producers and scroungers: A general model and its application to captive flocks of house sparrows. Anim Behav 29:543-550.

Beauchamp G, Giraldeau L-A, 1997. Patch exploitation in a producer-scrounger system: Test of a hypothesis using flocks of spice finches (Lonchura punctulata). Behav Ecol 8:54-59.

Bertram B, 1980. Vigilance and group size in ostriches. Anim Behav 28:278-286.

Blurton Jones NG, 1984. A selfish origin for human food sharing: tolerated theft. Ethol Sociobiol 5:1-3.

Blurton Jones NG, 1986. Fitness returns from resources and the outcome of contests: some implications for primatology and anthropology. In: Primate ontogeny, cognition, and social behavior, vol. 3 (Else JG, Lee PC, eds). Cambridge: Cambridge University Press; 393-406.

Blurton Jones NG, 1987. Tolerated theft, suggestions about the ecology and evolution of sharing, hoarding and scrounging. Soc Sci Inf 26:31-54.

Brown JL, 1964. The evolution of diversity in avian territorial systems. Wilson Bull 76:160-169.

Chapman MR, Kramer DL, 1996. Guarded resources: the effect of intruder number on the tactics and success of defenders and intruders. Anim Behav 52:83-94.

Clutton-Brock TH, Parker GA, 1995. Punishment in animal societies. Nature 373:209-216.

de Waal FBM, 1989. Food sharing and reciprocal obligations among chimpanzees. J Hum Evol 18:433-459.

Elgar MA, 1986. House sparrows establish foraging flocks by giving chirrup calls if the resources are divisible. Anim Behav 34:169-174.

Giraldeau L-A, Caraco T, 2000. Social foraging theory. Princeton, New Jersey: Princeton University Press.

Giraldeau L-A, Hogan JA, Clinchy MJ, 1990. The payoffs to producing and scrounging: What happens when patches are divisible? Ethology 85:132-146.
Goodall J, 1986. The chimpanzees of Gombe: Patterns of behavior. Cambridge: Harvard University Press.

Hamilton WD, 1964. The genetical evolution of social behavior. I, II. J Theor Biol 7:1-52.

Hauser MD, 1992. Costs of deception: cheaters are punished in rhesus monkeys (Macaca mulatta). Proc Natl Acad Sci USA 89:12137-12139.

Hauser MD, Marler P, 1993. Food-associated calls in rhesus macaques (Macaca mulatta): II. Costs and benefits of call production and suppression. Behav Ecol 4:206-212.

Hauser MD, Teixidor P, Fields L, Flaherty R, 1993. Food-elicited calls in chimpanzees: effects of food quantity and divisibility. Anim Behav 45:817-819.

Kummer H, Cords M, 1991. Cues of ownership in long-tailed macaques, Macaca fascicularis. Anim Behav 42:529-549.

Maynard Smith J, 1982. Evolution and the theory of games. Cambridge: Cambridge University Press.

Mesterton-Gibbons M, Dugatkin LA, 1999. On the evolution of delayed recruitment to food bonanzas. Behav Ecol 10:377-390.

Mitani JC, Watts DP, 2001. Why do chimpanzees hunt and share meat? Anim Behav 61:915-924.

Packer C, Abrams P, 1990. Should co-operative groups be more vigilant than selfish groups? J Theor Biol 142:341-357.

Perry S, Rose L, 1994. Begging and transfer of coati meat by whitefaced capuchin monkeys, Cebus caucinus. Primates 35:409-415.

Trivers RL, 1971. The evolution of reciprocal altruism. Q Rev Biol 46:35-57.

Vickery WL, Giraldeau L-A, Templeton JJ, Kramer DL, Chapman CA, 1991. Producers, scroungers, and group foraging. Am Nat 137:847-863.

Winterhalder B, 1996a. A marginal model of tolerated theft. Ethol Sociobiol 17:37-53.

Winterhalder B, 1996b. Social foraging and the behavioral ecology of intragroup resource transfers. Evol Anthropol 5:46-57.

Wrangham RW, 1975. The behavioural ecology of chimpanzees in Gombe National Park, Tanzania (PhD dissertation). Cambridge: Cambridge University.

Ydenberg RC, Giraldeau L-A, Kramer DL, 1986. Interference competition, payoff asymmetries, and the social relationships of central place foragers. Theor Popul Biol 30:26-44.

Zar JH, 1996. Biostatistical analysis, 3rd ed. Upper Saddle River, New Jersey: Prentice Hall. 